\title{
Alterations in Corneal Biomechanical and Topographic Features After Accelerated Crosslinking: I-Year Results
}

\author{
(1) Ahmet Kirgiz, ${ }^{1}$ (1) Sevil Karaman Erdur, ${ }^{2}$ () Kubra Serefoglu Cabuk, ${ }^{1}$ (i) Kursat Atalay, ${ }^{3}$ \\ (1) Senay Asik Nacaroglu ${ }^{3}$ \\ ${ }^{1}$ Department of Opthalmology, University of Health Sciences, Prof. Dr. N.Resat Belger Beyoglu Eye Training and \\ Research Hospital, Istanbul, Turkey \\ ${ }^{2}$ Department of Opthalmology, Istanbul Medipol University, Istanbul, Turkey \\ ${ }^{3}$ Department of Opthalmology, University of Health Sciences, Bagcilar Training and Research Hospital, Istanbul, Turkey
}

\begin{abstract}
Objectives: To determine the biomechanical and topographic alterations within the first year after accelerated crosslinking $(\mathrm{CXL})$ treatment in patients with keratoconus.

Methods: In this prospective study, 52 eyes of 52 patients with progressive keratoconus underwent accelerated CXL were included. All patients had a detailed preoperative ophthalmologic examination, including slit-lamp evaluation, Goldmann tonometry, fundoscopy, topography by Scheimpflug imaging (Sirius), and corneal biomechanical evaluation with a biomechanical waveform analysis device (ORA). Alterations in visual acuity and topographic findings were evaluated before the treatment and at 12 months follow-up. Corneal biomechanical features were obtained before the treatment, and at $I^{\text {st }}, 3^{\text {rd }}, 6^{\text {th }}$ and $12^{\text {th }}$ months.

Results: Uncorrected-visual acuity and best-corrected visual acuity both statistically significantly improved at $12^{\text {th }}$ month $(p=0.00 \mathrm{I})$. There were no statistically significant differences in keratometry values, whereas maximum $K$ (AKfront) and symmetry index front (SIfront) decreased significantly $(p=0.015$ and $p=0.009$, respectively). Corneal thinnest point and volume also decreased significantly at $12^{\text {th }}$ month $(p=0.00 \mathrm{I}$ for both). Goldmann-correlated intraocular $\mathrm{pressure}(\mathrm{IOPg})$ and corneal compensated IOP (IOPcc) values transiently increased in the first three months, while corneal hysteresis $(\mathrm{CH})$ and the corneal resistance factor (CRF) transiently decreased, with the difference not statistically significant $(p>0.05)$. However, central corneal thickness significantly decreased at the end of the $12^{\text {th }}$ month $(p=0.00 \mathrm{I})$.

Conclusion: Accelerated CXL seems to be effective in stopping the progression of keratoconus. Our findings showed transient alterations in biomechanical features, which will end with the preoperative values at the end of the $12^{\text {th }}$ month. Further studies are needed to demonstrate the changes in corneal biomechanics in vivo.

Keywords: Accelerated crosslinking, corneal biomechanics, corneal topography, corneal hysteresis, keratoconus.
\end{abstract}

\section{Introduction}

Keratoconus is a progressive, usually bilateral corneal ectasia characterized by corneal thinning and protrusion, progressive myopia, and irregular astigmatism (I). The only way shown to stop progression is the corneal collagen crosslinking $(C X L)(2,3)$.
$\mathrm{CXL}$ is a minimally invasive procedure that increases the biomechanical strength of the cornea through the induction of photochemically triggered cross-links within the collagen network using riboflavin and ultraviolet-A radiation (4, 5). Conventional $C X L$ was determined as a safe and efficient way of treatment in keratoconus in many studies (5,

Address for correspondence: Ahmet Kirgiz, MD. Saglik Bilimleri Universitesi, Oftalmoloji Anabilim Dali, Prof. Dr. N. Resat Belger Beyoglu Goz Egitim ve Arastirma Hastanesi, Istanbul, Turkey Phone: +90 5053974683 E-mail: ahmetk1@yahoo.com

Submitted Date: November 07, 2018 Accepted Date: July 09, 2019 Available Online Date: August 08, 2019

${ }^{\circledR}$ Copyright 2019 by Beyoglu Eye Training and Research Hospital - Available online at www.beyoglueye.com OPEN ACCESS This work is licensed under a Creative Commons Attribution-NonCommercial 4.0 International License. 
6). However, the procedure lasts approximately one hour. Theoretically, the same energy dose can be delivered in a shorter time with an accelerated modality $(7,8)$. In accelerated CXL, reported as the rapid, effective and safe alternative in keratoconus treatment, the same energy dose ensuring a proportional biological effect is delivered in a shorter exposure time by setting different UV-A powers $(9,10)$. The UV-A power could be set to 30,18 or $9 \mathrm{~mW} /$ $\mathrm{cm}^{2}$ to radiate cumulative dose of $5.4 \mathrm{~J} / \mathrm{cm}^{2}$ in a shorter time, such as 3,5 or 10 minutes, respectively. With the increasing use of these accelerated CXL protocols, studies on the long-term effects have begun to be published in recent years $(\mathrm{II}, \mathrm{I} 2)$.

Although it is shown in ex vivo that the rigidity of the cornea is increased 4.5 times in the human cornea by $\mathrm{CXL}$ (I3), it is important to evaluate the changes in corneal biomechanics after the treatment in vivo to understand the efficacy of the procedure. It is theoretically possible to evaluate the corneal biomechanical properties that may occur in the cornea with the ocular response analyzer (ORA) designed to obtain in vivo measurements (14). While several studies report the biomechanical changes after conventional $\mathrm{CXL}$ with the ORA device (I5-2I), the data about the results of accelerated CXL regarding the biomechanical features of the cornea are limited in the literature (22). In this study, we aimed to investigate the biomechanical and topographic alterations in 12 month period after accelerated collagen $\mathrm{CXL}$ treatment among patients with keratoconus.

\section{Methods}

In this prospective study, 52 eyes of 52 patients with progressive keratoconus who underwent accelerated $\mathrm{CXL}$ between July 2014 and January 2015, in Bagcilar Education and Research Hospital, Istanbul, Turkey were included. Patients who were followed up for 12 months regularly were included in this study. This study was approved by the local Ethics Committee. Progressive keratoconus was defined as an increase of 1.00 diopter (D) or more in the steepest keratometry $(\mathrm{K})$ measurement or the loss of at least two lines of best-corrected distance visual acuity in last I year (23). The exclusion criteria were as follows: patients younger than 18 or older than 40 years of age, patients with a corneal thickness less than $400 \mu$ at the thinnest point, patients with corneal scarring or severe dry eye, patients having a history of corneal surgery, or pregnant or lactating women during the course of this study.

All patients had a detailed preoperative ophthalmologic examination, including slit-lamp evaluation, Goldmann tonometry, fundoscopy, topography by Scheimpflug imaging (Sirius, Schwind Eye-Tech-Solutions GmbH, Germany), corneal biomechanical properties and intraocular pressure evaluation by Ocular Response Analyzer (Reichert Technologies, Buffalo, NY, USA). Visual acuity was obtained with Snellen charts and converted to LogMAR units for analysis. Uncorrected visual acuity (UCVA) and best-corrected visual acuity (BCVA) were both recorded.

The Sirius, a topographic device consisting of a combination of two rotating Scheimpflug cameras and a Placido disk, was used for topographical and central corneal thickness (CCT) measurements. Flat keratometry value $\left(\mathrm{K}_{1}\right)$, steep keratometry value $\left(\mathrm{K}_{2}\right)$, average keratometry value $\left(\mathrm{K}_{\text {avg }}\right)$, topographic cylindrical value (Cyl), apical keratoscopy front $\left(\mathrm{AK}_{\text {front }}\right)$, apical keratoscopy back $\left(\mathrm{AK}_{\text {back }}\right)$, symmetry index front $\left(\mathrm{SI}_{\text {front }}\right)$, symmetry index back $\left(\mathrm{SI}_{\text {back }}\right)$, corneal thinnest point (CTP), and corneal volume (CV) were recorded before the treatment and at 12 months follow-up. Apical keratoscopy front $\left(\mathrm{AK}_{\text {front }}\right)$ was defined as the steepest point of the anterior corneal surface, while apical keratoscopy back $\left(\mathrm{AK}_{\text {back }}\right)$ was defined as the steepest point of the posterior corneal surface. Symmetry index front $\left(\mathrm{Sl}_{\text {front }}\right)$, the symmetry index of the anterior curvature, was defined as the difference of the mean anterior tangential curvature of two circular zones centered on the vertical axis in the inferior and superior hemispheres. Symmetry index back $\left(\mathrm{SI}_{\text {back }}\right)$, the symmetry index of the posterior curvature, was defined as the difference of the mean posterior tangential curvature of two circular zones centered on the vertical axis in the inferior and superior hemispheres. All measurements were taken with the manufacturer's guideline by the same trained examiner.

The Ocular Response Analyzer (ORA) reports two intraocular pressure values: Goldmann-correlated IOP (IOPg) and corneal compensated IOP (IOPcc). Two different bidirectional (inward and outward) applanation pressure measurements were recorded by ORA. The difference between these two pressures is the corneal hysteresis $(\mathrm{CH})$, which is an indicator of corneal viscosity. Corneal resistance factor (CRF) is considered as the indicator of the overall resistance of the cornea that is mainly associated with the elastic properties of the cornea.

Alterations in visual acuity and topographic findings of study participants were evaluated before the treatment and at 12th month of follow-up. Corneal biomechanical properties were obtained before the treatment and at I, 3, 6, and 12 months following accelerated CXL.

\section{Surgical Technique}

Accelerated crosslinking has been performed to all patients. Initially, a topical anesthetic agent (Alcaine; Alcon Laboratories, Inc.) was administered and the central $8.0 \mathrm{~mm}$ epithelium was removed with a blunt spatula. Riboflavin with dextran $(0.1 \%$ in $20 \%$ dextran solution, Medicross, Ger- 
many) was administered topically every three minutes for 30 minutes. The cornea was aligned and exposed to UV-A $365 \mathrm{~nm}$ light for five minutes at an irradiance of $18 \mathrm{~mW} /$ cm2 (Peschke Meditrade, GmbH) (I I). During UV-A exposure, riboflavin administration was continued every minute. After the treatment, the eye surface was washed with 20.0 $\mathrm{mL}$ of a balanced salt solution. Postoperatively, antibiotic (Vigamox; Alcon Co., Inc.), corticosteroid drops (Lotemax; Bausch \& Lomb) and artificial tears (Refresh; Allergan) were administered; a soft contact lens bandage was placed. The contact lens was removed after the closure of the epithelial defect. Antibiotics and corticosteroid drops were continued four times daily for one week and two weeks, respectively.

\section{Statistical Analysis}

All analyses were performed with the Statistical Package for Social Sciences software (SPSS, Windows version 21.0; SPSS Inc.; Chicago, IL, USA). A P value of less than 0.05 was considered statistically significant. Topographic findings $\left(K_{\text {, }}\right.$, $\mathrm{K}_{2}, \mathrm{~K}_{\text {avg }}, \mathrm{AK}_{\text {front }}, \mathrm{AK}_{\text {back }}, \mathrm{SI}_{\text {front }}, \mathrm{SI}_{\text {back }}, \mathrm{Cyl}, \mathrm{CTP}$, and CV), BCVA and UCVA were compared using the paired Student-t test. Corneal biomechanical properties were compared using repeated-measures ANOVA with post hoc Tukey test. The correlations between CCT at 12 months, and each perioperative variable were evaluated using the Pearson correlation coefficient.

\section{Results}

Totally 52 eyes ( 28 right and 24 left) of 52 patients ( $18 \mathrm{fe}-$ male, 34 male) with a mean age of 24.15 \pm 6.75 (range: 18-39 years) years were included. Visual acuities and topographic findings of patients before the treatment and at 12 months follow-up are summarized in Table I.

There was a statistically significant improvement in the UCVA and BCVA after the I2-month visit (both $\mathrm{p}=0.00 \mathrm{I}$ ). The $\mathrm{AK}_{\text {front }}$ and $\mathrm{SI}_{\text {front }}$ values showed a significant decrease after 12 months compared with the preoperative values ( $p=0.015$, and $p=0.031$, respectively). The CTP and CV also revealed a significant decrease at the end of 12 -month visit (both $\mathrm{p}=0.00 \mathrm{I}$ ).

Alterations in corneal biomechanical properties during the 12-month follow-up are given in Table 2. Regarding these alterations, IOPcc and IOPg values transiently increased in the first three months; whereas $\mathrm{CH}$ and CRF values transiently decreased in first three months, although the changes were statistically insignificant. However, CCT significantly decreased at the end of 12 -month visit $(p=0.001)$ (Fig. I).

As regards the correlations, there was significant correlation between the mean CCT at $12^{\text {th }}$ month and baseline CCT, CTP, and CV ( $r=0.888, r=0.769, r=0.523$, respectively, $p=<0.00$ I for all); whereas no significant correlation was found between the mean CCT at $12^{\text {th }}$ month and other parameters ( $p>0.05$ for all).

Table I. Comparison of visual acuity and topographic findings between the preoperative and the 12 months of follow-up

\begin{tabular}{lccc} 
& $\begin{array}{c}\text { Baseline } \\
\text { Mean } \pm \text { SD }\end{array}$ & $\begin{array}{c}\mathbf{1 2}^{\text {th }} \text { month } \\
\text { Mean } \pm \text { SD }\end{array}$ & P* \\
\hline UCVA (LogMAR) & $0.71 \pm 0.32$ & $0.55 \pm 0.32$ & $<0.001$ \\
$\mathrm{BCVA}($ LogMAR) & $0.42 \pm 0.22$ & $0.26 \pm 0.14$ & $<0.001$ \\
$\mathrm{~K}_{1}(\mathrm{D})$ & $45.4 \pm 1.8$ & $45.4 \pm 2$ & 0.805 \\
$\mathrm{~K}_{2}(\mathrm{D})$ & $48.6 \pm 2.2$ & $48.6 \pm 2.4$ & 0.837 \\
$\mathrm{~K}_{\text {avg }}(\mathrm{D})$ & $46.9 \pm 1.9$ & $46.9 \pm 2.1$ & 0.944 \\
$\mathrm{Cyl}^{(D)}$ & $3.2 \pm 1.4$ & $3.1 \pm 1.4$ & 0.198 \\
$\mathrm{AK}_{\text {front }}(\mathrm{D})$ & $55.1 \pm 4.1$ & $54.6 \pm 4.2$ & 0.015 \\
$\mathrm{AK}_{\text {back }}(\mathrm{D})$ & $79.6 \pm 8.8$ & $83.9 \pm 11.2$ & 0.001 \\
$\mathrm{SI}_{\text {front }}(\mathrm{D})$ & $6.1 \pm 2.8$ & $5.8 \pm 2.8$ & 0.031 \\
$\mathrm{SI}_{\text {back }}(\mathrm{D})$ & $1.5 \pm 0.7$ & $1.6 \pm 0.7$ & 0.013 \\
$\mathrm{CTP}(\mu \mathrm{m})$ & $456 \pm 32$ & $424 \pm 48$ & 0.001 \\
$\left.\mathrm{CV}(\mathrm{mm})^{3}\right)$ & $55.8 \pm 3.3$ & $54.4 \pm 3.5$ & 0.001 \\
\hline
\end{tabular}

SD: standard deviation; UCVA: uncorrected visual acuity; BCVA: best corrected visual acuity; $\mathrm{K}_{1}$ : flat keratometry value; $\mathrm{K}_{2}$ : steep keratometry value; $\mathrm{K}_{\text {avg }}$ : average keratometry value; $\mathrm{Cyl}$ : topographic cylindrical value; $\mathrm{AK}_{\text {front }}$ : apical keratoscopy front; $\mathrm{AK}_{\text {back }}$ : apical keratoscopy back; $\mathrm{Sl}_{\text {front }}$ : symmetry index front; $\mathrm{Sl}_{\text {back }}$ : symmetry index back; CTP: corneal thinnest point; $\mathrm{CV}$ : corneal volume. *Paired samples $\mathrm{t}$ test. 


\begin{tabular}{|c|c|c|c|c|c|c|}
\hline & Preoperative & I st month & $3^{\text {rd }}$ month & $6^{\text {th }}$ month & $12^{\text {th }}$ month & $\mathbf{P} *$ \\
\hline \multicolumn{7}{|c|}{ IOPcc (mmHg) } \\
\hline Mean $\pm S D$ & $13.8 \pm 2.4$ & $14.5 \pm 2.9$ & $14.2 \pm 2.8$ & $13.7 \pm 2.9$ & $13.5 \pm 2.5$ & 0.21 \\
\hline Range & $7.6-19.3$ & $9.5-22.2$ & $9.6-21.2$ & $6.8-22.1$ & $7.6-19$ & \\
\hline \multicolumn{7}{|l|}{ IOPg (mmHg) } \\
\hline Mean $\pm S D$ & $10.6 \pm 2.8$ & $10.8 \pm 3.3$ & $10.6 \pm 3.3$ & $10.5 \pm 2.9$ & $10.4 \pm 2.8$ & 0.50 \\
\hline Range & $4.3-16.7$ & $5.6-19.4$ & $3.5-17.3$ & $5-18$ & $3.2-16.3$ & \\
\hline \multicolumn{7}{|l|}{$\mathrm{CH}(\mathrm{mmHg})$} \\
\hline Mean \pm SD & $8.5 \pm 1.4$ & $8.1 \pm 1.3$ & $8 \pm 1.6$ & $8.4 \pm 1.5$ & $8.6 \pm 1.2$ & 0.39 \\
\hline Range & $4.3-12.2$ & $5.9-12.9$ & $4.6-13$ & $6-13.5$ & $6-12$ & \\
\hline \multicolumn{7}{|l|}{ CRF (mmHg) } \\
\hline Mean $\pm S D$ & $7.3 \pm 1.7$ & $7 \pm 1.7$ & $7 \pm 1.7$ & $7.2 \pm 1.5$ & $7.4 \pm 1.6$ & 0.58 \\
\hline Range & $2.6-11.2$ & $4-12.7$ & $1.9-10.3$ & $4-11.5$ & $4.3-11$ & \\
\hline \multicolumn{7}{|l|}{ ССТТ $(\mathrm{m} \mu)$} \\
\hline Mean $\pm S D$ & $476 \pm 39$ & $444 \pm 49$ & $437 \pm 46$ & $45 I \pm 47$ & $459 \pm 47$ & 0.001 \\
\hline Range & $420-609$ & $37 \mid-634$ & $342-612$ & $366-621$ & $378-633$ & \\
\hline \multicolumn{7}{|c|}{$\begin{array}{l}\text { SD: standard deviation; IOPcc: corneal compensated intraocular pressure; IOPg: Goldmann-correlated } \\
\text { intraocular pressure; } \mathrm{CH} \text { : corneal hysteresis; CRF: corneal resistance factor; CCT: central corneal thickness } \mathbb{} \\
\text { measured with Sirius device. *Repeated measures ANOVA, post-hoc Tukey test. }\end{array}$} \\
\hline
\end{tabular}

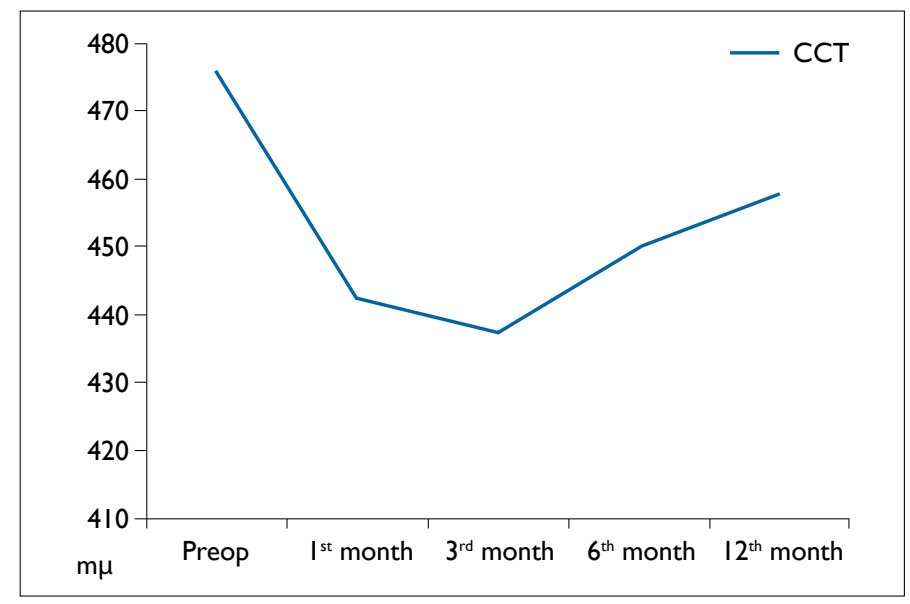

Figure I. Alterations in central corneal thickness (CCT) at postoperative 12 months after accelerated crosslinking.

\section{Discussion}

This study is one of the few studies in the literature evaluating biomechanical features along with topography changes following accelerated $C X L$ reporting at least I-year results (22). Both UCVA and BCVA statistically significantly improved in $12^{\text {th }}$ months of follow up with significant alterations in $\mathrm{AK}_{\text {front }}$ and $\mathrm{Sl}_{\text {front }}$ values of the cornea, demonstrating the efficacy of this method in controlling keratoconus. On the other hand, $\mathrm{CH}$ and $\mathrm{CRF}$ remained unchanged after $\mathrm{I} 2$ months of the treatment suggesting these parameters may not represent the exact biomechanical effects of accelerated CXL.

In CXL treatment, reactive oxygen species are thought to be produced, leading to the formation of covalent cross-links between collagen molecules, with a resulting stiffening of the stromal tissue. This strengthening of the corneal stroma decelerates the progression of keratoconus and ectasia and, in many cases, improves patients' visual, refractive, and topographic outcomes $(5,24)$. In that aspect, some alterations especially in corneal biomechanical properties are expected.

In the relevant literature, there are several studies about the alterations in topographic and corneal biomechanical properties after conventional CXL. Goldich et al. (I5) analyzed 10 eyes in the first six months after conventional $\mathrm{CXL}$ treatment and consistent with our results, they also reported transient nonsignificant elevations in $\mathrm{CH}$ and $\mathrm{CRF}$ values after $\mathrm{CXL}$. Sedaghat et al. (16) compared $\mathrm{CH}$ and $\mathrm{CRF}$ values in the first six months after conventional $C X L$ for keratoconus in 56 eyes of $5 \mathrm{I}$ patients and did not determine any significant alterations in $\mathrm{CH}, \mathrm{CRF}, \mathrm{CCT}$ and IOPg, but IOPcc was reported to be decreased significantly. In another study of Goldich et al. (17), I4 patients were assessed after conventional $C X L$ for 24 months and a significant improvement in BCVA with a decrease in the mean cylinder without any 
significant alterations in minimal corneal thickness, endothelial cell density, corneal hysteresis, or corneal resistance factor was reported. Greenstein et al. (18) investigated the corneal biomechanical changes in 69 eyes after conventional $\mathrm{CXL}$ for one year, and consistent with our results, they reported that there were not any alterations in $\mathrm{CH}$ or CRF values. In this study, we determined transient alterations in the first three months in IOPcc, IOPg, CRF and $\mathrm{CH}$ after accelerated $\mathrm{CXL}$ which were not statistically significant but a significant decrease in CCT in the $12^{\text {th }}$ month of follow-up.

In another recent study investigating corneal topographical and biomechanical properties in the Ist year after conventional CXL in 97 eyes and compatible with our results they also reported a significant improvement in UCVA and BCVA values with a significant decrease in CCT and corneal volume without any significant alterations in $\mathrm{CH}$ and $\mathrm{CRF}$. However, diversely from our results, they reported a significant decrease in average keratometry value (19). Interestingly, Beckman et al. (20) investigated the biomechanical effects of conventional CXL in 29 eyes of 28 patients and reported increased $\mathrm{CH}$ values with applanation resonance tonometer but not with ORA. They also determined a significant decrease in CCT in Ist and $6^{\text {th }}$ months of follow-up after treatment. Terai et al. (24) defined ORA as providing invaluable information for defining biomechanical conditions of the cornea. We used ORA to determine the corneal biomechanical properties in this study and did not determine any significant alterations in the corneal biomechanical properties during the first year after accelerated CXL. Consistent with our results, Çağıl et al. (25) did not find any significant alterations in $\mathrm{CH}$ and $\mathrm{CRF}$ but observed a significant decrease in CCT at postoperative six months after conventional CXL. In a recent and the only one study investigating the corneal biomechanical alterations after accelerated CXL, Uzel et al. (22) found out that second-generation parameters ( $\mathrm{pl}$ area, $\mathrm{p} 2$ area, $\mathrm{h} 2$, and dive 2) were more sensitive than $\mathrm{CH}$ and $\mathrm{CRF}$ with a new ORA software (version 2.04).

$\mathrm{CH}$ is an indicator of corneal viscosity, and CRF is considered as the indicator of the overall resistance of the cornea that is mainly associated with the elasticity of the cornea. After CXL, accelerated or conventional, decrease in $\mathrm{CH}$ and/ or CRF values is expected since CXL increases the biomechanical strength of the cornea. However, in this study, we determined that, though transient alterations in $\mathrm{CH}$ or CRF might be seen in first months after accelerated $C X L$, there was not a statistically significant increase at the end of $12^{\text {th }}$ month compared with the preoperative values. There may be some reasons for these insignificant results. Firstly, the decrease in CCT may have prevented the accurate measurement of corneal biomechanics. Secondly, the ORA device may be inadequate in evaluating the corneal biomechanical properties due to the changing in corneal collagen configuration after CXL. The transient alterations seen in the first three months in $\mathrm{CH}$ and $\mathrm{CRF}$ may be due to the insufficient ORA signals which were probably affected by optical irregularity.

The data about the effects of accelerated CXL are increasing in the literature. Elbaz et al. (26) assessed the topographical, visual, and refractive effects of accelerated CXL in keratoconus at $6^{\text {th }}$ and $12^{\text {th }}$ months of follow-up and reported that there was not a statistically significant alteration in corrected distance visual acuity and mean refractive cylinder, but uncorrected distance visual acuity was improved. Moreover, all corneal parameters, including Ksteep, Kflat, average $\mathrm{K}$, corneal astigmatism, were stable at 6 and 12 months in all patients. Mita et al. (27) evaluated the effectiveness of accelerated CXL for keratoconus in first six months after treatment in 39 eyes of 22 patients and reported a statistically significant improvement in UCVA and a significant decrease in the mean maximum keratometry readings without any changes in the endothelial cell density. Although alterations in Ist year after accelerated CXL were investigated in a few studies before, there are also some recent studies reporting the differences between conventional $C X L$ and accelerated CXL. Chow et al. (28) compared one-year outcomes of 2 $\mathrm{CXL}$ methods in patients with progressive keratoconus and reported insignificantly flattened maximum and minimum keratometry values and significantly reduced corneal thickness in both groups. Moreover, similar to our results significant improvements in UCVA and BCVA were reported. Hashemi et al. (29) compared the six months results of 2 CXL methods in 62 eyes and reported similar clinical efficacies. Tomita et al. (30) reported that there were no statistically significant differences in the postoperative changes in the keratometric readings or the corneal biomechanical responses between the accelerated and conventional CXL.

In correlation analysis, we found no statistically significant relation between CCT at 12 months versus preoperative corneal biomechanical properties. However, there was a significant correlation between CCT at 12 months versus preoperative CCT, CTP and CV. In that aspect, in all patients, preoperative CCT, CTP and CV should be evaluated carefully. Unlike with our results, Viswanathan et al. (3I) determined a positive correlation of both $\mathrm{CH}$ and CRF with CCT in the normal, keratoconic and crosslinked eyes.

Maximum keratometry value $\left(A K_{\text {front }}\right)$ was defined as one of the topographic indicators of CXL success and reported to be stable or decreased after CXL (32). Likewise, significantly decreased $A K_{\text {front }}$ values were also reported in this study in $12^{\text {th }}$-month control after the treatment showing that accelerated $\mathrm{CXL}$ is effective in stopping the progression of keratoconus. 
The main limitations of our study were the small sample size and lack of a control group consisting of patients who underwent conventional CXL. However, the investigation of both topographic and corneal biomechanical properties in the 12 month period is the strength of this study.

In conclusion, in the $12^{\text {th }}$ month after accelerated $C X L$, determination of improved UCVA and BCVA, together with the stable $\mathrm{K}$ values, decreased $\mathrm{AK}_{\text {front }}$ and $\mathrm{SI}_{\text {front }}$ suggests the long-term efficacy of this procedure. Our findings showed transient alterations in biomechanical features, which will end with the preoperative values at the end of $12^{\text {th }}$ month. Further studies with larger groups and longer follow-up periods are required to determine the exact effects of accelerated CXL on corneal topography and advanced technologies are needed to assess the corneal biomechanical alterations more accurately.

\section{Disclosures}

Ethics Committee Approval: Bagcilar Training and Research Hospital Clinical Research Ethics Committee, May 17, 2016, no: 459. Peer-review: Externally peer-reviewed.

Conflict of Interest: None declared.

Authorship Contributions: Involved in design and conduct of the study (AK, SKE, KSC); preparation and review of the study (AK, SKE, SAN); data collection (AK, KSC, KA); and statistical analysis (AK, KA, SAN).

\section{References}

I. Romero-Jiménez M, Santodomingo-Rubido J, Wolffsohn JS. Keratoconus: a review. Cont Lens Anterior Eye 2010;33:I57-66.

2. Farjadnia M, Naderan M. Corneal cross-linking treatment of keratoconus. Oman J Ophthalmol 2015;8:86-9I. [CrossRef]

3. Wollensak G, Spoerl E, Seiler T. Riboflavin/ultraviolet-a-induced collagen crosslinking for the treatment of keratoconus. Am J Ophthalmol 2003;135:620-7. [CrossRef]

4. Raiskup-Wolf F, Hoyer A, Spoerl E, Pillunat LE. Collagen crosslinking with riboflavin and ultraviolet-A light in keratoconus: long-term results. J Cataract Refract Surg 2008;34:79680I. [CrossRef]

5. Wittig-Silva C, Chan E, Islam FM, Wu T, Whiting M, Snibson GR. A randomized, controlled trial of corneal collagen crosslinking in progressive keratoconus: three-year results. Ophthalmology 2014;121:812-21. [CrossRef]

6. Caporossi A, Mazzotta C, Baiocchi S, Caporossi T. Long-term results of riboflavin ultraviolet a corneal collagen cross-linking for keratoconus in Italy: the Siena eye cross study. Am J Ophthalmol 2010; 149:585-93. [CrossRef]

7. Brindley GS. The Bunsen-Roscoe law for the human eye at very short durations. J Physiol 1952; I I8: I35-9. [CrossRef]

8. Wernli J, Schumacher S, Spoerl E, Mrochen M. The efficacy of corneal cross-linking shows a sudden decrease with very high intensity UV light and short treatment time. Invest Ophthalmol
Vis Sci 2013;54:I I 76-80. [CrossRef]

9. Schumacher S, Oeftiger L, Mrochen M. Equivalence of biomechanical changes induced by rapid and standard cornealcrosslinking, using riboflavin and ultraviolet radiation. Invest Ophthalmol Vis Sci 201 I;52:9048-52. [CrossRef]

10. Bouheraoua N, Jouve L, Borderie V, Laroche L. Three Different Protocols of Corneal Collagen Crosslinking in Keratoconus: Conventional, Accelerated and lontophoresis. J Vis Exp 2015; 105. [CrossRef]

I I. Kurt T, Ozgurhan EB, Yildirim Y, Akcay BI, Cosar MG, Bozkurt $\mathrm{E}$, et al. Accelerated $(18 \mathrm{~mW} / \mathrm{cm}(2))$ Corneal Cross-Linking for Progressive Keratoconus: 18-Month Results. J Ocul Pharmacol Ther 2016;32:186-91. [CrossRef]

I2. Ting DSJ, Rana-Rahman R, Chen Y, Bell D, Danjoux JP, Morgan SJ, et al. Effectiveness and safety of accelerated $(9 \mathrm{~mW} / \mathrm{cm} 2)$ corneal collagen cross-linking for progressive keratoconus: a 24-month follow-up. Eye (Lond) 2019;33:812-8. [CrossRef]

13. Wollensak G, Spoerl E, Seiler T. Stress-strain measurements of human and porcine corneas after riboflavin-ultraviolet-A-induced cross-linking. J Cataract Refract Surg 2003;29: I780-5.

14. Luce DA. Determining in vivo biomechanical properties of the cornea with an ocular response analyzer. J Cataract Refract Surg 2005;31:156-62. [CrossRef]

I5. Goldich Y, Barkana Y, Morad Y, Hartstein M, Avni I, Zadok D. Can we measure corneal biomechanical changes after collagen cross-linking in eyes with keratoconus?--a pilot study. Cornea 2009;28:498-502.

16. Sedaghat M, Naderi M, Zarei-Ghanavati M. Biomechanical parameters of the cornea after collagen crosslinking measured by waveform analysis. J Cataract Refract Surg 2010;36:1728-31.

17. Goldich Y, Marcovich AL, Barkana Y, Mandel Y, Hirsh A, Morad $Y$, et al. Clinical and corneal biomechanical changes after collagen cross-linking with riboflavin and UV irradiation in patients with progressive keratoconus: results after 2 years of follow-up. Cornea 2012;31:609-14. [CrossRef]

18. Greenstein SA, Fry KL, Hersh PS. In vivo biomechanical changes after corneal collagen cross-linking for keratoconus and corneal ectasia: I-year analysis of a randomized, controlled, clinical trial. Cornea 20I2;31:2I-5. [CrossRef]

19. Sedaghat M, Bagheri M, Ghavami S, Bamdad S. Changes in corneal topography and biomechanical properties after collagen cross linking for keratoconus: I-year results. Middle East Afr J Ophthalmol 2015;22:2I2-9. [CrossRef]

20. Beckman Rehnman J, Behndig A, Hallberg P, Lindén C. Increased corneal hysteresis after corneal collagen crosslinking: a study based on applanation resonance technology. JAMA Ophthalmol 20|4;132:1426-32. [CrossRef]

21. Küçümen RB, Şahan B, Yıldırım CA, Çiftçi F. Evaluation of Corneal Biomechanical Changes After Collagen Crosslinking in Patients with Progressive Keratoconus by Ocular Response Analyzer. Turk J Ophthalmol 2018;48:160-5. [CrossRef] 
22. Uzel MM, Koc M, Can C, Polat S, Yılmazbaş P, lleri D. Effect of accelerated corneal crosslinking on ocular response analyzer waveform-derived parameters in progressive keratoconus. Arq Bras Oftalmol 2019;82: 18-24. [CrossRef]

23. Sorkin N, Varssano D. Corneal collagen crosslinking: a systematic review. Ophthalmologica 2014;232:10-27.

24. Terai N, Raiskup F, Haustein M, Pillunat LE, Spoerl E. Identification of biomechanical properties of the cornea: the ocular response analyzer. Curr Eye Res 2012;37:553-62. [CrossRef]

25. Çağıl N, Saraç Ö, Akçay E, Aksoy B, Uğurlu N, Ayan M. Keratokonus hastalarında korneal kollajen çapraz bağlama tedavisinin kısa dönemde kornea biyomekaniği üzerine etkileri. MN Oftalmoloji 2014;21:I52-6.

26. Elbaz U, Shen C, Lichtinger A, Zauberman NA, Goldich Y, Chan $\mathrm{CC}$, et al. Accelerated $(9-\mathrm{mW} / \mathrm{cm} 2)$ corneal collagen crosslinking for keratoconus-A I-year follow-up. Cornea 20I4;33:76973. [CrossRef]

27. Mita M, Waring GO 4th, Tomita M. High-irradiance accelerated collagen crosslinking for the treatment of keratoconus: six-month results. J Cataract Refract Surg 2014;40:1032-40.

28. Chow VW, Chan TC, Yu M, Wong VW, Jhanji V. One-year outcomes of conventional and accelerated collagen crosslinking in progressive keratoconus. Sci Rep 2015;5:14425. [CrossRef]

29. Hashemi H, Fotouhi A, Miraftab M, Bahrmandy H, Seyedian MA, Amanzadeh K, et al. Short-term comparison of accelerated and standard methods of corneal collagen crosslinking. J Cataract Refract Surg 2015;41:533-40. [CrossRef]

30. Tomita M, Mita M, Huseynova T. Accelerated versus conventional corneal collagen crosslinking. J Cataract Refract Surg 2014;40:1013-20.

3I. Viswanathan D, Kumar NL, Males JJ, Graham SL. Relationship of Structural Characteristics to Biomechanical Profile in Normal, Keratoconic, and Crosslinked Eyes. Cornea 20I5;34:79I-6.

32. Raiskup F, Theuring A, Pillunat LE, Spoerl E. Corneal collagen crosslinking with riboflavin and ultraviolet-A light in progressive keratoconus: ten-year results. J Cataract Refract Surg 20I5;4I:4I-6. [CrossRef] 